ISSN: 2638-6062

\title{
Ludopathy: Play to Lose
}

\author{
Gabriel Miranda Nava* \\ Department of Neurology, Hospital Center, Mexico, USA
}

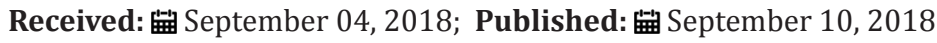

*Corresponding author: Gabriel Miranda Nava, Chief of Neurology, Hospital Center, Mexico, USA

\section{Opinion}

This is a relatively new concept, and if you do not know what it is about, dear reader, I will ask you the following: please go at about 10.45 in the morning to a place that has among its premises a Caliente, a Play City, Yak, Emotion, or others to name a few, you will see a long line of impatient people, mostly women, ready to enter, with greater punctuality than when they go for the children to schools, or even to the funeral of the grandmother. The concept of pathological gambling refers to an irresistible desire to play, which goes hand in hand with a visible bet, with an implicit risk of money or kind; This desire is accompanied by extreme anxiety, and when the person sitting on the bench is already calm and the first move is made, it is necessary to say the financial problems to which they, their partners and children, submit themselves; here we list the characteristics of this condition already listed in the international classification of diseases since 1992:

a) The failure to resist the urge to play.

b) The growing sensation of excitement and

c) Tension before going to play and

d) The pleasant experience or relief at the time of playing.
The gamblers are hardly assumed as sick or addicted to gambling, due to ignorance or fear of social rejection, and the stigma that their condition is a vice and not a disease, but ultimately meet the characteristics of entry to the club of the addicts as they even get to murder to steal and be able to settle their gambling debts, or with an increase in the frequency by 20 times more than the rate of suicides before the impossibility of continuing to play and betting; 1 out of 5 gamblers will have a suicidal event in their life.

According to the World Health Organization (WHO), 3\% of adults suffer from it, with a 3:1 ratio of more women than men, and above all of the elderly (that bingo and the domain would not seem so harmful. It is estimated that in Mexico there are around 2 million gambling addicts, being a subclinical situation until the sudden advent of the casinos, and nobody could see or have the proper prevention. It is an addiction, it behaves like an addiction, it kills as such, it costs the same or more, but the difference is that it is new, we hardly know about it in this country and there is no laboratory study that indicates its severity, but as any Addictive origin, grows with indifference, lack of attention and care, ignorance and a touch of evil.

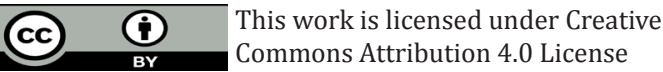

To Submit Your Article Click Here: Submit Article

DOI: $10.32474 /$ PRJFGS.2018.02.000135

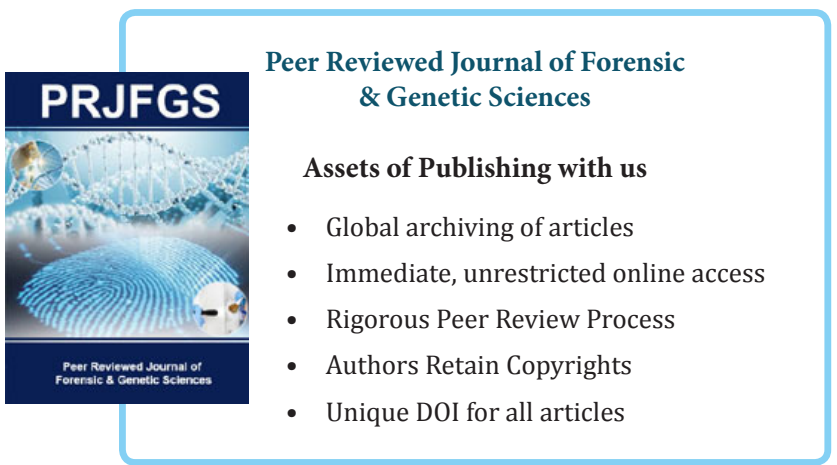

